\title{
Antiplasmodial Activity of Angiotensin II Analogs
}

\author{
Danieli Melo de Freitas and Vani Xavier Oliveira Junior \\ Centro de Ciências Naturais e Humanas, Universidade Federal do ABC, Santo André, 09210-580, Brazil
}

\section{Introduction}

Malaria is an infectious disease caused by parasites of the genus Plasmodium. According to the World Health Organization, 584,000 people died of malaria in the world, and $78 \%$ of these cases were children under five [1]. Antimalarial compounds have been studied including angiotensin II (AII) with $88 \%$ inactivation efficiency towards $P$. gallinaceum parasites [2]. Other authors have studied the importance of each amino acid residue applying the Ala-scan method as well as amino acid deletions of the molecule $[3,4]$.

The malaria cycle in the intermediate host begins with a bite from female mosquitos. Protozoa in the form of sporozoites are present in the salivary gland of the mosquito. These enter the bloodstream and reach the liver cells. The sporozoites begin to divide several times resulting in a large number of parasites in the form of merozoites. The liver merozoites invade red blood cells and initiate the socalled erythrocytic cycle. At this stage, the infected individual has mainly anemia and sporadic fever [5].

Based on this information, the present work proposes an analysis into a better hydrophobic/hydrophilic balance in angiotensin analogs (DRVYIHPF) to increase the antimalarial activity in the sporozoites of Plasmodium galinaceum. This technology increases efficacy without sideeffects [6].

\section{Results and Discussion}

The peptides were synthesized manually by Fmoc strategy with Wang resin. The amino acid couplings were carried out with a 2.5 -fold molar excess of the Fmoc-protected amino acid with DIC/HOBt in $\mathrm{DCM} / \mathrm{DMF}$ for $2 \mathrm{~h}$ at room temperature. Peptides were cleaved from the resin in a reaction with $90 \%$ TFA, $5 \%$ water and $5 \%$ anisole comprising a concentration of $10 \mathrm{ml} / \mathrm{g}$ of peptidyl resin. At the end of reaction, the peptide was treated with ethyl ether, extracted with $0.1 \%$ TFA/60 \% ACN in water and lyophilized. The analogs of thirteen of these were satisfactory, and the resulting peptides had a chromatographic purity higher than $95 \%$; mass characterization by LC/MS-ESI confirmed that the purified peptides were in agreement with the expected theoretical values. The antiplasmodial activity was determined in vitro by fluorescence microscopy after $1 \mathrm{~h}$ of incubation of the parasites with each peptide in the presence of ethidium bromide. The results are reported as percent fluorescent sporozoites. A conformational study of peptides was done with the circular dichroism (CD) technique for peptides in $15 \mathrm{mmol}$ PBS, $10 \mathrm{mmol}$ SDS, 50\% MeOH (v/v), and 50\% TFE (v/v).

The hydrophobic/hydrophilic balance was studied by replacing the six amino acid residues with amino acids of different polarity. The amino acids proline and arginine were not modified. The antiplasmodial activity was reduced when these amino acids as well as phenylalanine and tyrosine were replaced by Ala. Clearly, these amino acids are important to the structure of the molecule [3]. The amino acid deletion study also showed the importance of proline to antiplasmodial activity of the molecule. The altered sequence had $14 \%$ residual activity; the arginine deletion showed an activity of $43 \%$ [4]. These studies have shown that any amino acid deletion causes a reduction in activity - this is more pronounced for proline and arginine. The [ $\left.\mathrm{Arg}^{2}\right]$-AII favors electrostatic interactions between the peptide ends [3].

The synthesized analogs had their biological activity tested in sporozoites of P. gallinaceum, and the activity was calculated from the total fluorescent sporozoites. The synthetic analogs showed a significant difference in antimalarial activity versus AII.

Replacement of any amino acid in AII decreased antiplasmodial activity. Analogs 1 - [His $\left.{ }^{1}\right]$-AII and $8-\left[\right.$ Asn $\left.^{1}\right]$-AII activities were $35 \%$ and $71 \%$ of baseline, respectively. This relative decrease may be because AII has a compact folded structure due to the proximity of their amino terminus and carboxy-terminus [7].

Conformational analysis indicates that the angiotensin peptides with a greater antiplasmodial activity form a $\beta$ structure [8]. Analogs 1 and 8 also had a tendency to form $\beta$ structures. 
Modifications of the analogs $9-\left[\mathrm{Lys}^{3}\right], 11-\left[\mathrm{Glu}^{3}\right]$ and $12-\left[\mathrm{Ser}^{3}\right]$ showed decreased activity. The hydrophobic character of valine (the peptide containing the region Asp-Arg-Val) is important to break the plasmodium membrane. AII can interact with the negatively-charged membrane via the positively charged $N$-terminal portion [3]. The deletion of valine decreased the antiplasmodial activity by $23 \%$ [4]. The decrease in antiplasmodial activity may impede the interaction between the proline and valine in the chain [7]. This promotes the stabilization of the folded conformation of AII as evidenced by the conformational change in the circular dichroism.

Tyrosine plays an important role in the conformation of the molecule forming a hydrophobic cluster isoleucine and histidine. Analog $7-\left[\mathrm{Phe}^{4}\right]$-AII showed an activity of $62 \%$, but there was no difference in conformation. Position 4 is important for peptide activity, and Tyr 4 may expose the guanidine portion of Arg to be an important interaction for the overall peptide activity [3].

Analog $6\left[\mathrm{Tyr}^{8}\right]$-AII $68 \%$ activity was statistically equal to 7 . The analog position 8 is important for the biological activity of this molecule. It showed a similar difference in conformation. Although a difference has occurred, it was not very pronounced because the change involved two aromatic compounds. These amino acids with aromatic side chains may also play an important role in the peptide structure and its interaction with the membrane.

Analog 4- $\left[\operatorname{Trp}^{6}\right]$-AII, 5 [Asp $\left.{ }^{6}\right]$-AII and 13- [Ser 6 -AII had 40\% activity. The conformational study showed that conformational changes occur.

Analogs 2- $\left[\mathrm{Arg}^{5}\right]$-AII, 3- [Ans $\left.{ }^{5}\right]-\mathrm{AII}$ and 10- [Asp ${ }^{5}$-AII showed an activity of $70 \%, 52 \%$, and $21 \%$. This altered a bulky isoleucine - its substitution may affect the amphipathic properties of the AII because this amino acid is one of the hydrophobic residues in the trainer cluster. The conformational analysis showed that for the three analogs, there was a change in the conformation of the molecule. The substitution of isoleucine by other polar amino acids can prevent the formation of the hydrophobic cluster. It changes the conformation of the molecule and reduces its biological activity. In addition, its side chain interacts with the terminal amino group of aspartic acid [9].

With occasional changes made in the AII structure, we found that these synthesized analogs showed changes in biological activity versus AII. These results allow a better understanding of the importance of each of the residues in AII. The analogs exhibit a reduction in biological activity for all the sequences studied. This highlights the importance of amino acid residues.

\section{Acknowledgments}

This researchwas supported by Coordenação de Aperfeiçoamento de Pessoal de Nível Superior (Capes) and Fundação de Amparo a Pesquisa (FAPESP).

\section{References}

1. World Malaria Report. http://www.who.int/malaria/world_malaria_report_2014/worldmalaria report2014.pdf

2. Maciel, C., Oliveira, V.X. Jr., Fázio, M.A., Nacif-Pimenta, R., Miranda, A., Pimenta, P.F., Capurro, M.L. PLoS ONE 3, e3296, (2008), http://dx.doi.org/10.1371/journal.pone.0003296

3. Silva, A.F., Bastos, E.L., Torres, M.T., Costa-da-Silva, A.L., Ioshino, R.S., Capurro, M.L., Alves, F.L.,

Miranda, A., Freitas, R.F., Oliveira, V. J. Pept. Science 2, 640-648 (2014), http://dx.doi.org/10.1002/psc.2641

4. Ferreira, L.H., Silva, A.F., Torres, M.T., Pedron, C.N., Capurro. M.L., Alves, F.L., Miranda, A., Oliveira,

V.X. Jr. Inter. J. Pept. Res. Therap. 20, 553-564 (2014), http://dx.doi.org/10.1007/s10989-014-9425-9

5. Garcia, L.S. Clin. Lab. Med. 30, 93-129 (2010), http://dx.doi.org/10.1016/j.cll.2009.10.001

6. Vukelic, S., Griendling, K.K. Circ. Res. 114, 754-757 (2014),

http://dx.doi.org/10.1161/CIRCRESAHA.114.303045

7. Tzakos, A.G., Bonvin, A.M.J.J., Troganis, A, Cordopatis, P, Amzel,M.L., Gerothanassis, I.P., Nuland, N.A.J. Eur. J. Biochem. 849-860 (2003), http://dx.doi.org/10.1046/j.1432-1033.2003.03441.x

8. Greff, D., Fermandjian, S., Fromageot, P., Khosla, M.C., Smeby, R.R., Bumpus, F.M. Eur. J. Biochem. 61, 297-305 (1976), http://doi/10.1111/j.1432-1033.1976.tb10022.x

9. Tzakos, A.G., Gerothanassis, I.P., Troganis, A.N. Curr. Top Med. Chem.4, 431-444 (2004), http://dx.doi.org/10.2174/1568026043451375 